\title{
LA BUENA FE EN MATERIA CONTRACTUAL EN LA UNIVERSIDAD DE GUANAJUATO. LÍMITES INTERNOS Y EXTERNOS
}

\section{The Good Faith In Contractual Matters In The University Of Guanajuato. Internal And External Limits}

\author{
Marisol LÓPEZ VALLEJO* \\ Margarita CRUZ TORRES ${ }^{* *}$
}

\section{Sumario:}

I. La buena fe. Un principio en el contrato. II. Límites a las expresiones de la buena fe. Caso Universidad de Guanajuato III. Límites internos a la expresión. Disposiciones que regulan las manifestaciones materiales de la buena fe al interior de la Institución Universitaria IV. Limites y Normativa externa V. Conclusiones

Resumen: La formalización y ejecución de las expresiones de la buena fe materializadas en convenios transciende a los requisitos de validez señalados en las disposiciones legales de materia civil, base toral de los acuerdos. Pero éstos no se suscriben al margen de la normativa universitaria, puesto que hay límites de carácter interno y externo que acotan estas manifestaciones de intención, dependiendo de su origen público y de su relación con la actividad sustantiva de la Universidad, contando con órganos colegiados y dependencias dedicadas a la vigilancia del actuar de sus integrantes y servidores públicos y a la aplicación de sanciones en caso de rebasar los límites legales impuestos.

Palabras clave: Buena fe, Convenio, Derecho civil, Límites, Transparencia

Abstract: The formalization and execution of the expressions of good faith materialized in agreements transcends the requirements of validity indicated in the legal dispositions of civil matters as the general basis of the agreements. But these are not subscribed to outside the university regulations, since there are internal and external limits that limit these manifestations of intention, depending on their public origin and their relation with the substantive activity of the University, counting on collegiate bodies and dependencies

* Licenciada en Derecho por la Universidad Autónoma de Querétaro, candidata a Maestra en Administración Pública, con Especialidad en Derecho Constitucional y Amparo, coordinadora de convenios y contratos de la Oficina del Abogado General de la Universidad de Guanajuato.

** Doctora en Derecho, Maestra en Derecho Penal, Profesora de la Facultad de Derecho de la Universidad Autónoma de Querétaro, Miembro de la Asociación de Filosofía del Derecho para el Mundo Latino. 
dedicated to the vigilance of the actions of its members and public servants and to the application of sanctions in case of exceeding the legal limits imposed.

Keywords: Good faith, Contract, Civil law, Limits, Transparency

\section{Introducción}

En una universidad, los pactos jurídicos se preparan con la intención inspiradora volitiva de vincular a las partes. Tal intención está enmarcada por el principio de la buena fe, mismo que sustenta el actuar de las personas con intención de relacionarse. Esta convicción es inherente a los individuos que integran a una comunidad universitaria frente a la sociedad, la cual espera eficacia en los tratos bilaterales de una institución educativa.

La buena fe recorre todo el campo institucional, se actualiza en la confianza de crear acuerdos, emerge y se hace tangible en el preámbulo, formalización y cumplimiento de los convenios y contratos. El principio de la buena fe no recae en individualismos, más bien, su fulgor está delimitado -sin ser restrictivo y categóricamente- por normas de interés público que establecen los alcances de la voluntad suprema de las partes.

\section{La buena fe. Un principio en el contrato}

Una característica constitutiva del lenguaje jurídico es que tiene un carácter reductivo respecto a la riqueza y variedad del lenguaje ordinario, y es importante que este reduccionismo, aunque necesario para la teoría, no sacrifique elementos indispensables para los fines propios de la misma ${ }^{1}$. En el lenguaje legal, la buena fe se entenderá a raíz de su significado axiológico. De acuerdo con Manuel Atienza:

Es a partir del valor jurídico, que por antonomasia es el de justicia, que en su acepción más estricta, la justicia aparece como un característico valor social, y más en particular, como un valor específicamente jurídico, la justicia se entiende como el criterio que cabe utilizar para valorar un sistema jurídico, en consecuencia, la justicia vendría a ser una parte o una especificación de los valores morales: aquellos que hacen referencia a relaciones, normas o actos jurídicos, entre los que están los contratos. $^{2}$

Desde el punto de vista de Ramón Sánchez Medal, se distinguen dos conceptos de buena fe: en primer lugar, se trata de un principio de carácter ético, fundamentalmente, conforme al cual, los hombres en sus relaciones sociales $-\mathrm{y}$, por lo tanto, las partes en todos los contratos- deben proceder con sinceridad, lealtad y honradez y con el ánimo de no lesionar ni engañar a nadie ${ }^{3}$. A ella se refería Ulpiano en su sentencia del Digesto: Grave esta fidem fallere (grave cosa es traicionar la confianza) ${ }^{4}$.

\footnotetext{
${ }^{1}$ Comanducci, Paolo (2004), Razonamiento jurídico, elementos para un modelo, México, Distribuciones Fontamara, p. 25.

2 Atienza, Manuel (2011) Introducción al derecho, México, Editorial Fontamara, pp. 84-85.

3 Sánchez Medal, Ramón (1991) De los contratos civiles, 11ª. ed., México, Porrúa, p. 47.

${ }^{4}$ Ídem.
} 
En el antiguo derecho romano la buena fe constituyó un elemento indispensable en la vida jurídica: sola fides suficit (sólo la palabra basta); Nihil prius fide (nada antes que la fe). Fides es lealtad a la palabra dada y actúa como una fuerza vinculante del acto ${ }^{5}$. La cohesión social, la conciencia del deber, la honestidad y la mutua confianza tienen un trasfondo que sólo se descubre a través de la buena $\mathrm{fe}^{6}$. Se habla de la buena fe como base toral de los contratos e incluso se concibe con la sinergia de los principios generales del derecho que blindan nuestra vida y sus distintas expresiones. El presente análisis trata la relevancia de la buena fe en la celebración de los pactos jurídicos, así como de sus límites y alcances.

José de Jesús López Monroy, en su texto El Principio de la buena fe en el derecho civil, señala que la buena fe no es otra cosa sino la voluntad en cuanto que se dirige ciertamente al evento previsto ${ }^{7}$; en este caso, sería el acuerdo de voluntades. En contraste, hay quienes identifican a la buena fe como un adjetivo de la voluntad y defienden la postura que la considera como el elemento determinante para las relaciones jurídicas que exige lealtad de las partes. Aporta el jurista Juan Ricardo Jiménez Gómez ${ }^{8}$ :

La buena fe es un atributo volitivo requerido, antes, en y después de la celebración del contrato, vale decir, en la preparación, celebración en sentido estricto y ejecución del pacto [...] la buena fe debe existir concomitantemente en la vida misma del contrato. [...] Una exigencia de comportamiento congruente con una actitud psicológica animada de un contenido ético que se exterioriza al verificarse el pacto. ${ }^{9}$

Tratar el tema de los contratos y el valor de la buena fe, nos llama a lo aportado por Ignacio Galindo Garfias: La buena fe es un principio inspirador del derecho legislado y del derecho consuetudinario que se encuentra condicionando a la norma jurídica [...] la conducta humana debe sujetarse al principio de la buena fe, elemento primario esencial $y$, por lo tanto, imprescindible del deber jurídico ${ }^{10}$.

5 Lastra Lastra, José Manuel (2003), “La buena fe en el trabajo: ¿Un principio que se difumina?”, Revista de la Facultad de Derecho de México, núm. 240, p. 109. [en línea] disponible en: https://revistas-colaboracion.juridicas.unam.mx/index/php/rev-facultad-derecho-mx/article/view/28653/25908 (consultada el 31 de enero de 2018).

${ }^{6}$ Ídem.

7 López Monroy, José de Jesús (1986), "El Principio de la buena fe en el derecho civil", Revista de la

Facultad de Derecho de México, 1986, núm. 145-146-147, p.165. [en línea] disponible en: https://revistas-colaboracion.juridicas.unam.mx/index.php/rev-facultad-derecho-mx/article/view/27614/24943 (consultada el 5 de febrero del 2018).

8 JimÉnez GómeZ, Juan Ricardo (1985), "El principio de la buena fe en la teoría general del contrato" en Galindo Garfias, Ignacio, et.al., Un siglo de derecho civil mexicano: memoria del II Coloquio Nacional de Derecho Civil. 1884-1984, México, Universidad Nacional Autónoma de México, pp. 189-190.

9 SÁnchez Medal, op.cit. nota 3, pp. 47-48. A esta primera significación de buena fe, podría llamársele buena fe-vinculante o buena fe-norma, en virtud de que se identifica con un principio moral que rige la conducta de las partes y las obliga a preparar celebrar y sobre todo, a ejecutar los contratos, sin atenerse sólo a lo expresamente pactado o a la letra del convenio, sino a ajustarse también a la naturaleza misma de las prestaciones convenidas y del contrato celebrado. En un segundo sentido puede tomarse la buena fe como buena fe-convalidante o error-buena fe, que implica una especie de error en que se encuentra una de las partes al celebrar un determinado contrato o al realizar ciertos actos jurídicos. Este error no vicia el contrato ni lo anula [...] se trata de un error que purifica al contrato y lo hace inatacable [...] a esta buena fe suele designársele bajo el nombre de protección de la confianza o principio del respeto a la apariencia jurídica y se reduce fundamentalmente a la tutela de la buena fe por cuanto que el que obra de buena fe [...] debe ser protegido.

${ }^{10}$ Galindo Garfias, Ignacio (1981), "Estudios de derecho civil”, México, UNAM, Instituto de Investiga- 
La relevancia de la buena fe abarca el orden jurídico en su totalidad y más allá de la materia civil que ocupa nuestro estudio, pues son abrumadoras las normativas que remiten de forma supletoria al derecho civil. Así, la buena fe se entiende como un principio rector del orden civil, por lo que resultará aplicable a todo el marco legal.

El profesor Ernesto Gutiérrez y González, citando a Carnelutti, distingue entre buena fe objetiva y buena fe subjetiva, donde la primera es la regla de conducta que se exterioriza en el campo de los Ordenamientos; y, la segunda, aparece como una guía para la intención ${ }^{11}$. Este contraste, sin embargo, no corresponde a nuestra exposición de noción de bonne foi.

Por su parte, Nicolás Coviello arguye (teoría de la imprevisión):

La buena fe es bilateral, así como en interés del declarante exigen ella que el que recibe una declaración no tome las palabras al pie de la letra, sino que atienda a la intención, asi también en interés del que recibe la declaración exige que a la expresión de la voluntad se atribuya el significado normal, según los usos de la vida y la práctica de los negocios ${ }^{12}$

Postura de la cual disiente Ignacio Galindo Garfias en su trabajo El Principio de la Buena fe en el Derecho Civil ${ }^{13}$. La posición de Coviello resulta contrastante con las reglas de interpretación del Código Civil que, en caso de duda, se estará empleando en el sentido literal de la voluntad de las partes.

Entre los discursos localizados sobre el término axiológico de la buena fe, está el del profesor Juan Ricardo Jiménez Gómez ${ }^{14}$, quien señala sus funciones: un principio jurídico, una regla ${ }^{15}$ de conducta que impone al sujeto límites inherentes a un comportamiento éticamente adecuado -o esperado, porque nadie realiza un contrato con la intención de no cumplirlo-, un límite objetivo del alcance del derecho y de la obligación en las relaciones jurídicas ${ }^{16}$. La

ciones Jurídicas, p. 359. [en línea] disponible en: https://archivos.juridicas.unam.mx/www/bjv/detalle-libro/876-estudios-de-derecho-civil (consultada el 21 de febrero de 2018).

${ }^{11}$ Gutiérrez Y González, Ernesto (1982), "El Principio de la buena fe en el derecho civil”, Revista de la Facultad de Derecho de México, s.p.i,, núm. 124-125-126, p. 621. [en línea] disponible en: https:// revistas-colaboracion.juridicas.unam.mx/index.php/rev-facultad-derecho-mx/article/view/27427/24767 (consultada el 5 de febrero del 2018).

${ }^{12}$ Coviello, Nicolás (1938), Doctrina General del Derecho Civil, trad. Felipe de J. Tena, México, Unión Tipográfica Editorial Hispano-Americana, p. 443.

${ }^{13}$ Cfr. Galindo Garfías, Ignacio, op. cit., nota 8, p. 741.

${ }^{14}$ JimÉnez Gómez, Juan Ricardo, op. cit., nota 8, p. 191: decir que la buena fe circunscribe intención y creencias, influencia en el actuar y la manifestación hacia el otro contratante; y converge con la postura citada por aquel de que [...] la buena fe radica en el ánimo del sujeto autor de determinada conducta que exterioriza (o se oculta) la intención de aquel que observa un comportamiento [...] para el Derecho.

${ }^{15} \mathrm{Cfr}$ Robert Alexy, citado por Manuel Atienza: la distinción entre principios y reglas, es que los principios son normas que ordenan que se realice algo en la mayor medida posible, en relación con las posibilidades jurídicas y fácticas [...] son mandatos de optimización que se caracterizan porque pueden ser cumplidos en diversos grados [...] en cambio las reglas son normas que exigen un cumplimiento pleno y en esta medida pueden ser solo cumplidas o incumplidas. En ATIEnZA, Manuel y Ruiz Manero, Juan (1951), Sobre Principios y Reglas, p.108. En línea. Disponible en: http://www.cervantesvirtual.com/descargaPdf/ sobre-principios-y-reglas-O.pdf (consultada el 27 de mayo del 2018).

${ }_{16}$ Según Juan Ricardo Jiménez Gómez, los requisitos de la buena fe son: a) continuidad. El estado anímico del contratante, que refleje la confianza en el contratante y la creencia de situación [...] que debe ir adscrito a toda la vida del contrato [...] que no deber ser fraccionada en orden al principio de conservación 
buena fe involucra la preparación, celebración o ejecución del contrato, sus expresiones y su comprobación, etapas observables en distintas manifestaciones verbales, escritas o materiales ${ }^{17}$. Comprende que las expresiones de la buena fe se refieren a la exteriorización de ese estado anímico del contratante, y que es viable ejemplificar con hechos la buena fe: por medio de la entrega de un producto, la ejecución de una obra o el pago de un contrato.

El valor que imprimen los servidores públicos universitarios se desempeña con espíritu de lealtad y compromiso de la palabra dada y sentido de cumplimiento dentro de los límites que enmarcan su labor en la vida pública universitaria.

\section{Límites a las expresiones de la buena fe. Caso Universidad de Guanajuato}

Se puede describir una norma (y los hechos sociales que la establecen) sin recurrir al concepto de razón. Es un hecho fehaciente que los juristas y abogados pueden determinar la existencia de las normas jurídicas (y sus contenidos) sin necesidad de hablar de razones para esta acción ${ }^{18}$. Los conceptos fundamentales de nuestro lenguaje jurídico son los derechos (subjetivos) y los deberes, y el principal objeto del derecho es la determinación de los derechos y deberes de los individuos y su aplicación práctica ${ }^{19}$.

Este estudio parte de la reforma académica y administrativa que amplió la oferta educativa del organismo público autónomo denominado Universidad de Guanajuato ${ }^{20}$.

\subsection{Escritas o materiales}

Múltiple es el rigor normativo en las expresiones de buena fe de una institución pública universitaria como es la Universidad de Guanajuato. No son pocas las disposiciones legales que reglamentan las manifestaciones de buena fe, en las cuales, las voluntades son reguladas por la formalidad e interpretación literal en aras de la eficiencia, entendida como el mayor beneficio a menor costo. Lo anterior puede considerarse como uno de los componentes esenciales de una sociedad justa, aunque, evidentemente, no es el único ni el más importante. Es un valor que puede estar en relación inversa con otro de los componentes fundamentales de la idea de justicia, el principio de igualdad ${ }^{21}$. Podría discutirse y argumen-

del contrato. b) Objetividad [...] se refiere al sentido común del alcance o contenido ético de la buena fe, mismo que está circunscrito por un criterio espacio-temporal que lo determina. Son reflejo del sentir común de la sociedad, en un conjunto de relaciones jurídicas normales y regulares, que el sujeto, como integrantes de la sociedad, debe conocer y observar. c) Especificidad [...] la intención y la conducta de que consta la buena fe, deben estar referidas al contrato de manera directa, de modo que exista correspondencia ente idea determinante de la voluntad y el hecho materia del pacto [...] debe concretarse una relación finalística entre la buena fe y la realización del contrato. JiMÉNEz GómEZ, Juan Ricardo, op. cit., nota 8, pp.195-196.

${ }^{17}$ Ibídem., p.196.

${ }^{18}$ Tamayo Y Salmorán, Rolando (2007), Razonamiento y argumentación jurídica. El paradigma de la racionalidad y la ciencia del derecho, México, UNAM, p. 203.

${ }^{19}$ Olivecrona, Karl (2004), Lenguaje Jurídico y Realidad, Editorial Fontamara, p.7.

${ }^{20}$ Exposición de Motivos del Dictamen de la Comisión de Gobernación y Puntos Constitucionales del Congreso del Estado de la Quincuagésima Novena Legislatura a la Ley Orgánica de la Universidad de Guanajuato publicada en el Periódico Oficial número 96, tercera parte del 15 de junio de 2007. [en línea], disponible en: http://www.ugto.mx/images/pdf/normatividad/ley-organica-universidad-guanajuato.pdf

${ }^{21}$ Véase sobre este punto los trabajos de PeCes-BARba, G. (1984), Los valores superiores, Madrid, Tecnos, 
tarse que los criterios que un hombre debe respetar en situaciones de racionalidad colectiva son más ventajosos para sus intereses que la maximización estricta ${ }^{22}$. Los criterios que los servidores públicos deben atender, por las ventajas o beneficios colectivos universitarios, se ejemplifican en los límites ${ }^{23}$ puestos al ecosistema universitario, y los cuales son referidos a distintas razones del origen público, como su actividad sustantiva y el tipo de financiamiento, por nombrar algunas. $Y$ es que estamos inmersos en una sociedad donde comulgan intenciones y relaciones jurídicas a las que es necesario desarrollar de manera normal -como piedra angular de la objetividad ${ }^{24}$ - para llevar aquélla a un orden justo.

Partiendo de la buena fe -inherente a la persona- y de la verdad como fruto de la racionalidad científica, encontraremos aquélla en las formas periciales y desde las pruebas científicas y tecnológicas. Pero si la verdad es una construcción, entonces las formas de presentarse será la construcción de un discurso que se sustenta en la concatenación lógica, racional, razonable y lingüística de las diferentes narraciones (narración en primera persona del indiciado, narración en tercera persona desde las testimoniales, narraciones explicativas desde los informes médicos y periciales, etc.) que obran en el expediente ${ }^{25}$.

La buena fe está enmarcada por la autodisciplina, no entendida como individualismo, y por el principio de la voluntad de las partes es la suprema ley de los contratos ${ }^{26}$. Sin embargo, encontrar límites para la buena fe no soslaya la libertad contractual que tienen los contratantes, porque el contenido del contrato puede ser pactado a merced de las partes, siempre sustentadas en el respeto a las normas imperativas.

Los contratos dan a las partes seguridad: en torno a la seguridad jurídica se dice que es la certeza, que es la confianza que se deriva de que un pacto o convenio previo con otra persona, será respetado por ésta, lo que se traduce en la confiabilidad de que cumplirá lo acordado ${ }^{27}$. Una adecuada concepción de seguridad jurídica es la capacidad que nos proporciona el derecho de prever, hasta cierto punto, la conducta humana y las consecuencias de dicha conducta. Esta capacidad de previsión no es sólo limitada, sino también variable -es decir, no todos los sistemas jurídicos ofrecen la misma seguridad jurídica-, lo cual nos va a permitir distinguir 3 niveles de seguridad: orden, certeza y seguridad en sentido estricto ${ }^{28}$.

Según D'Eufemia ${ }^{29}$, el límite a la regla general de libertad contractual representa la excepción expresamente prevista por el ordenamiento jurídico, siendo indudable que, por el reconocimiento de la autonomía de las partes, éstas gozan de libertad para fijar el contenido del contrato y, precisamente en virtud de ese privilegio, no deberán imponer unilateralmente su voluntad una a la otra. La autonomía de las partes puede limitarse, y de

y el de Pérez Luño, A.E., El principio de igualdad en la Constitución Española, Anuario de Filosofía del Derecho. cit. por CAlSAMiglia, Albert (1993), Racionalidad y Eficiencia del derecho, México, Editorial Fontamara, p. 28.

${ }^{22}$ CAlsamiglia, Albert, op. cit., nota 21, p. 9.

${ }^{23}$ La regla, mientras por un lado importa poder desplegar la propia actividad en interés propio, importa, por el otro, un límite a tal actividad, a fin de que sean respetados los intereses ajenos. Coviello, Nicolás, op. cit., nota 12, p. 2.

${ }^{24}$ Véase Objetividad, nota 16.

${ }^{25}$ Ribeiro Toral, Gerardo (2007), Verdad y argumentación jurídica, México, Porrúa, p. 28-29.

${ }^{26}$ Aguilar Carvajal, Leopoldo (1964), Contratos Civiles, México, Hagtam, p. 15.

${ }^{27}$ Flores García, Fernando (2008), Los fines del derecho, México, Porrúa, p. 16.

${ }^{28}$ Atienza, Manuel op. cit., nota 2, p. 105.

${ }^{29}$ Cit. por MuÑoz, Luis (1971), Derecho Civil Mexicano, t. III, México, Ediciones Modelo, p.176. 
hecho lo está, por las normas imperativas de los ordenamientos jurídicos. Mientras que, para Luis Muñoz, los límites a la libertad contractual pueden deducirse fácilmente concibiéndolos como contrafigura de los supuestos de autonomía privada. Del mismo modo, la autonomía privada puede limitarse, y de hecho lo está, por las normas imperativas de los ordenamientos jurídicos ${ }^{30}$.

En la actualidad todas las relaciones que tiene la Universidad de Guanajuato tienen repercusión en el interés social, al ser miembro de una colectividad. En este orden público, los límites emergen y encuentran su sustento en el principio de seguridad jurídica. Sin ocasión de disensos entre la supremacía y el orden cronológico del principio de seguridad jurídica, que en opinión de algunos estudiosos es la base del orden jurídico, se sostiene que la buena fe se concibe a partir de la seguridad jurídica. Establecer las condiciones de la contratación pública con base en el principio de la seguridad jurídica implica su cumplimiento.

El sistema jurídico que transciende a la Universidad de Guanajuato está en los artículos: 3 fracción 7 de la Constitución Política de los Estados Unidos Mexicanos, estableciendo su autonomía y la responsabilidad de gobernarse a sí misma, así como en su artículo 3 de su Ley Orgánica vigente ${ }^{31}$; sin embargo, esta autonomía no la exenta de atender límites para sus actividades y actos jurídicos.

El Código Civil para el Estado de Guanajuato ${ }^{32}$ establece los acuerdos verbales, señalando que basta el mero consentimiento para la perfección de los contratos. Sin embargo, la realidad universitaria está llamada de forma unánime a que las expresiones de la buena fe sean materializadas, esto es, que existan medios tangibles para verificar la intención y actuación de las partes ${ }^{33}$. Dentro de la comunidad universitaria están los alumnos, profesores o académicos y los administrativos, pero en el presente trabajo sólo haremos eco de la relación que como funcionarios públicos mantienen estos últimos, ya que actúan como servidores públicos con buena intención, pero subyacen a los límites legales impuestos.

\section{Límites internos a la expresión. Disposiciones que regulan las manifestaciones materiales de la buena fe al interior de la Institución universitaria}

El propósito de todas las disposiciones jurídicas, pronunciamientos judiciales, contratos y otros actos jurídicos es influir en la conducta de los hombres y dirigirla de ciertas ma-

\footnotetext{
${ }^{30}$ MuÑoz, Luis (1973), Teoría General del Contrato, México, Cárdenas, Editor y Distribuidor, p. 149.

${ }^{31}$ Reformas Ley Orgánica de la Universidad de Guanajuato, Periódico Oficial del Gobierno del Estado, 29 de mayo del 2018 [en línea], disponible en: http://periodico.guanajuato.gob.mx/downloadfile?dir $=a-$ nio_2016\&file $=$ PO_207_7ma_Parte_20161229_0112_10.pdf

${ }^{32}$ Congreso Constitucional del Estado Libre y Soberano de Guanajuato (2016), Código civil para el estado de Guanajuato, Periódico Oficial del Gobierno del estado de Guanajuato, 29 de mayo del 2018, [en línea] disponible en: http://imug.guanajuato.gob.mx/wp-content/uploads/2017/05/C\%C3\%B3digo-Civil-para-el-Estado-de-Guanajuato.pdf

${ }^{33}$ Previsto en el artículo 1283 del Código Civil para el Estado de Guanajuato: los contratos se perfeccionan y surten efectos entre las partes por el mero consentimiento; excepto aquellos que deben revestir una forma establecida por la ley. Desde que se perfeccionan, obligan a los contratantes no sólo al cumplimiento de lo expresamente pactado, sino también a las consecuencias que, según su naturaleza, sean conformes a la equidad, a la buena fe, a la costumbre, al uso o a la ley. Igualmente el artículo 1319 del citado código señala que en los contratos civiles cada uno se obliga en la manera y términos que aparezca que quiso obligarse, sin que para la validez del contrato se requieran formalidades determinadas, fuera de los casos expresamente designados por la ley. Ídem., p. 221.
} 
neras. El lenguaje jurídico - plasmado en los pactos de igual naturaleza- tiene que ser considerado, en primer lugar, como un medio para este fin. Es un instrumento de control social y de comunicación social llamado, lenguaje directivo ${ }^{34}$. Las distintas disposiciones jurídicas que influyen en la actividad de la Universidad de Guanajuato, en cuanto a la celebración de relaciones bilaterales, son:

\section{La Ley Orgánica de la Universidad de Guanajuato}

En el artículo 62 se contempla la facultad del Consejo General Universitario para incluir, en el Estatuto Orgánico, un apartado sobre la responsabilidad del personal administrativo de la Universidad, cuyo procedimiento e imposición de sanciones serán encauzados por el órgano interno de control de la Universidad ${ }^{35}$.

\section{Estatuto Orgánico de la Universidad de Guanajuato}

En el artículo 84 se fijan las responsabilidades del personal administrativo, y el artículo 85 dicta las responsabilidades y procedimientos aplicables al personal académico y alumnos ${ }^{36}$. Sin perjuicio de que, conforme al artículo 60 Bis de la Ley Orgánica de la Universidad de Guanajuato, el Órgano Interno de Control de la Universidad proponga normas que regulen los instrumentos y procedimientos de control interno, los cuales serán aprobados, en su caso, por la Comisión de Vigilancia en términos del artículo 59 fracción quinta reformada.

\section{Estatuto Académico}

Este ordenamiento forma parte del marco normativo que menciona nuestro tema, pero desde diverso ámbito. Acerca de la docencia nos ocuparemos en otro momento ${ }^{37}$.

${ }^{34}$ Olivecrona, Karl op. cit., nota 19, p. 47.

${ }^{35}$ En el artículo 60 Bis el Órgano Interno de Control de la Universidad será responsable del control, evaluación y desarrollo administrativo de la Universidad; cobrando importancia la atribución señalada en la fracción 12 para conocer e investigar las conductas de los servidores públicos de la Universidad que puedan constituir responsabilidades administrativas, así como substanciar los procedimientos correspondientes conforme a lo establecido en la Ley de Responsabilidades aplicable, así como realizar la defensa jurídica de sus resoluciones. Secretaría de Gobierno (2016), Reformas Ley Orgánica de la Universidad de Guanajuato, op. cit., nota 32.

${ }^{36}$ El artículo 84 del Estatuto Orgánico prevé, en los términos de lo dispuesto por el artículo 62 de la Ley Orgánica, las obligaciones del personal administrativo de la Universidad serán reguladas en la Ley de la materia. Ibidem., p. 65. Señala el artículo 85: la reglamentación respectiva especificará las consecuencias derivadas de la infracción al marco normativo interno de la Universidad por parte del personal académico y de los alumnos. Los órganos competentes para la aplicación de dichas consecuencias serán, según corresponda a su ámbito, las Comisión de Honor y Justicia del Consejo General Universitario, los Consejos Universitarios de Campus, los Consejos Divisionales, el Consejo Académico del Nivel Medio Superior y las Academias. Ídem.

${ }^{37}$ Sólo de forma representativa el artículo 120 del Estatuto Académico determina que corresponde a la Comisión de Honor y Justicia del Consejo General Universitario, sancionar conforme a la reglamentación que al efecto se expida. En la sesión extraordinaria número 02 del 20 de marzo del 2018, publicada en la Gaceta Universitaria el 22 de marzo del 2018, el pleno del Consejo General Universitario aprobó el Reglamento Académico de la Universidad de Guanajuato con las modificaciones y precisiones vertidas, el cual se publicará y entrará en vigor una que se hayan armonizado todos los ordenamientos, lo cual significa una modificatoria en la normativa institucional próxima. Ídem. 
Código de Ética de la Universidad de Guanajuato. Aprobado por el Consejo General Universitario el 19 de noviembre del 2010

En el Plan de Desarrollo Institucional 2010-2020 se habla de la actividad universitaria enmarcándola en los principios de Verdad, Libertad, Respeto, Responsabilidad y Justicia.

Para nuestro estudio, el actuar universitario debe tener como sustentos inspiradores el valor de la Libertad, el valor del Respeto, así como el valor de Responsabilidad ${ }^{38}$.

A este respecto, el Estatuto Orgánico de la Universidad de Guanajuato establece en sus artículos 47, 84 y 85 que compete al órgano colegiado, entiéndase Comisión de Honor y Justicia, dictaminar sobre el quebranto a los límites de las manifestaciones materiales y aplicar la sanción a las conductas del personal académico y de los alumnos, aunque ya quedó establecido que el alumnado no es objeto de estudio.

Asimismo, en cuanto a límites impuestos por obligaciones de transparencia, la Universidad, a través del Comité de Transparencia ${ }^{39}$, consultable en el Portal correspondiente de

${ }^{38}$ Tiene un significado el valor de la libertad, cuya conducta se describe a partir de permitir y facilitar el ejercicio de las libertades que las distintas normas reconocen a los individuos. Ejercer las libertades que la ley concede a todos los individuos [...] Ejercer la libertad de expresión en cualquiera de sus modalidades. El respeto se establece como Actuar y conducirse con apego a los ordenamientos legales. La responsabilidad, según el Código de Ética, es tomar las decisiones relativas a su encargo o actividad, con base en la Ley, en la normativa y en la filosofía institucional para salvaguardar la vida de la Institución. Justicia es reconocer los méritos académicos, artísticos, de superación social y administrativa que desarrollen los miembros de la comunidad universitaria y de la sociedad en general.

39 Mediante el Acuerdo del Comité de Transparencia de la Universidad de Guanajuato se establecen las competencias de las áreas universitarias respecto de las obligaciones de transparencia: 1. Marco normativo aplicable al sujeto obligado, en el que deberá incluirse leyes, códigos, reglamentos, decretos de creación, manuales administrativos, reglas de operación, criterios, políticas, entre otros. Área Universitaria competente: Oficina del Abogado General, fundamento normativo: Acuerdo que establece la estructura administrativa de la Rectoría General de la Universidad de Guanajuato. Consideraciones: La normatividad vigente aplicable a la Universidad de Guanajuato es un insumo necesario para la Oficina del Abogado General para el cumplimiento de sus atribuciones. De acuerdo con las funciones de la Oficina del Abogado General, prevista en el anexo único del acuerdo en cita, en su fracción XIII, se establece la atribución de Asesorar a las autoridades unipersonales, órganos de gobierno y colegiados, para la interpretación, alcance y ámbito de validez de la normatividad interna y legislación en general. De acuerdo con lo transcrito supra líneas, para poder llevar a cabo dicha atribución, la Oficina del Abogado General debe contar con la compilación de la normatividad actualizada tanto interna cuanto externa aplicable a la Universidad de Guanajuato. En razón de lo anterior compete a dicha área universitaria la actualización y publicación de la información relacionada con el marco normativo aplicable a la Universidad de Guanajuato.

Los convenios de coordinación de concertación con los sectores social y privado. Área Universitaria competente: Oficina del Abogado General, fundamento normativo: Acuerdo que establece la estructura administrativa de la Rectoría General de la Universidad de Guanajuato. Consideraciones: En atención con el anexo único del acuerdo de referencia, la Oficina del Abogado General, según las fracciones IX y $\mathrm{X}$, tiene las siguientes funciones: Redactar y revisar convenios, contratos y documentos sobre diversos actos en que la Universidad intervenga, además, Tener un archivo debidamente clasificado en todos los convenios y contratos de la institución. En este contexto, las funciones de la Oficina del Abogado General son determinantes, en el sentido de que es dicha área universitaria la que genera y resguarda los convenios y contratos en los que interviene la Universidad. Por tanto, es competencia de la Oficina del Abogado General cumplir con la obligación de transparencia en cita, a efectos de publicar y actualizar la información en los términos de dicha obligación. Acuerdo aprobado por el Comité de Transparencia de la Universidad de Guanajuato en su primera sesión ordinaria del 09 de junio de 2017 y publicado en la Gaceta Universitaria el 27 de junio de 2017, pp. 2-16. 
la Universidad de Guanajuato, atiende el mandato constitucional del derecho de acceso a la información ${ }^{40}$.

\section{Límites y Normativa externa}

Según Víctor Castrillón y Luna ${ }^{41}$, no puede haber individualismo absoluto, porque los derechos de cada hombre no tienen más límites que los que aseguran a otros miembros de la sociedad el goce de los mismos derechos. Retomando la postura de Planiol y Ripert ${ }^{42}$, todo acto jurídico es obra de una o varias voluntades individuales y señalan que la voluntad de los particulares no es absolutamente libre, sino que gozan de una autonomía parcial. Esta libertad contractual compromete a la voluntad de las partes y se limita para crear normas jurídicas. Aunque los contratantes fijen el contenido del pacto jurídico porque gozan de esa libertad, esta voluntad puede limitarse y de hecho lo está por las distintas normas imperativas. La voluntad encuentra restricciones y no actúa en forma suprema. Desde un punto de vista axiológico, la libertad contractual encuentra su razón en la libertad de modificar su propia situación.

La buena fe y el principio de seguridad jurídica son la atmósfera que preside la vida de los contratos en la Universidad de Guanajuato; si renunciamos a estos, condenamos a los contratos a su degradación. El principio de seguridad jurídica, como ya quedó apuntado, brinda certeza a las relaciones jurídicas que tiene la Universidad de Guanajuato, porque las partes, al tener claro las limitantes, saben a qué atenerse ${ }^{43}$.

La seguridad jurídica nos da certeza de las consecuencias contractuales. Al inicio del presente comentamos que la buena fe tiene alcance a la ejecución del contrato y esta parte se regula también por disposiciones emanadas de cuerpos legislativos externos a la Universidad de Guanajuato, pero no alejados al quehacer universitario. Nombrar un ejemplo de lo anterior sería que la Universidad, como ejecutor de gasto, se torna en sujeto obligado a cumplir la legislación en materia de programación, presupuestación, aprobación, ejercicio, control y evaluación de los ingresos y egresos públicos federales que reciben las universidades públicas, como es el caso de la Universidad de Guanajuato ${ }^{44}$. Esta aplicabilidad se realiza con base en criterios de legalidad, honestidad, eficiencia, eficacia, economía, racionalidad, austeridad, transparencia, control, rendición de cuentas y equidad de género.

40 Secretaría de Gobierno (2016), Reformas Ley Orgánica de la Universidad de Guanajuato, Periódico Oficial del Gobierno del Estado, 29 de mayo del 2018 [en línea], disponible en: http://periodico.guanajuato. gob.mx/downloadfile?dir=anio_2016\&file=PO_207_7ma_Parte_20161229_0112_10.pdf

${ }^{41}$ Hay dos limitaciones ineludibles a la contratación: 1) que se deriva del interés público que está por encima de la voluntad individual; 2) la segunda de la técnica jurídica sobre la que tampoco puede prevalecer el capricho de los contratantes. CASTRILlón Y LunA, Víctor (2008), "La libertad contractual", Revista de la Facultad de Derecho de México, núm. 250, p. 156. [en línea] disponible en: https://revistas.unam.mx/ indez.php/rfdm/article/view/60936/53740 (Consultada el día 7 de mayo del 2018).

42 Ibídem., p. 158.

${ }^{43}$ Rodríguez-Arana, Jaime (2013), "El principio general del derecho de confianza legítima", Revista Ciencia Jurídica, Universidad de Guanajuato, núm. 1-4, julio, pp. 67-69.

${ }^{44}$ Cfr. Estado de necesidad. Ahora se pacta de acuerdo con el estado de necesidad, según lo explorado por el autor, el consentimiento está condicionado y la voluntad está totalmente determinada por el estado de necesidad: En realidad, ya no encajan dentro del acto jurídico que denominaremos voluntario, porque la voluntad ha dejado de ser, en ellos, un elemento esencial, para ser sustituida por la necesidad. De BuEN LozAno, Néstor (2004), "La decadencia del contrato" con dos apéndices Veinte Años Después y Los tenues suspiros de la libertad contractual, $4^{\mathrm{a}}$. ed., México, Porrúa, p. 254. 
Adentrándonos en el análisis de las reglas que norman la intención y limitan la exteriorización, pese a que emergen de distintos órganos legislativos trascienden a la actividad universitaria que desea comprometerse en pactos jurídicos, como lo cita la Constitución Política para el Estado de Guanajuato acerca de la responsabilidad de los servidores públicos de los organismos a los que la ley otorgue autonomía, como la Universidad, en sus actos u omisiones, del artículo 122 al 124. En el discurso jurídico del poder legislativo y de la administración del nivel federal y estatal se emiten las normas de conducta que ordenarán límites a los acuerdos.

\section{La Ley General de Responsabilidades Administrativas ${ }^{45}$}

Esta regulación federal dicta la competencia de los órganos de control interno de las dependencias, regulando las actividades de los servidores públicos que integran la Universidad de Guanajuato.

\section{Ley de Responsabilidades Administrativas para el Estado de Guanajuato ${ }^{46}$}

Si la actuación se hace al margen de los límites, esta Ley señala la competencia de los órganos internos de control, como la instancia de la Universidad de Guanajuato, para proceder en materia de responsabilidades ${ }^{47}$. Se aplicará en tanto se actualicen las hipótesis previstas en el artículo 12; para nosotros cobra importancia la fracción siete, en el caso de contratos, convenios y concesiones como acuerdos jurídicos.

Hay que hacer notar que existen límites al rubro de financiamiento, lo cual hace referencia al recurso público federal que deviene de un ramo autónomo específico previsto en el Presupuesto de Egresos de la Federación para la infraestructura universitaria, y se tendrán que priorizar límites puestos por normas federales a la actividad institucional.

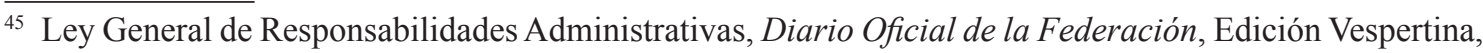
núm. 14, 2016, p. 60.

De acuerdo al artículo 7 fracción $1^{\circ}$ los servidores públicos observarán en el desempeño de su empleo, cargo o comisión, los principios de disciplina, legalidad, objetividad, profesionalismo, honradez, lealtad para la efectiva aplicación de dichos principios, los servidores públicos observarán las siguientes directrices: actuar conforme a lo que las leyes, reglamentos y demás disposiciones jurídicas les atribuyen a su empleo, cargo o comisión, por lo que deben conocer y cumplir las disposiciones que regulan el ejercicio de sus funciones, facultades y atribuciones;

La fracción $3^{\circ}$, satisfacer el interés superior de las necesidades colectivas por encima de intereses particulares, personales o ajenos al interés general y bienestar de la población.

La fracción 6 administrar los recursos públicos que estén bajo su responsabilidad, sujetándose a los principios de eficiencia, eficacia, economía, transparencia y honradez para satisfacer los objetivos a los que están destinados.

En el punto $8^{\circ}$ : corresponder a la confianza que la sociedad les ha conferido.

${ }^{46}$ Secretaría de Gobierno (2017), Ley de Responsabilidades Administrativas para el Estado de Guanajuato, 29 de mayo del 2018 [en línea], disponible en: http://periodico.guanajuato.gob.mx/downloadfile?dir $=a-$ nio_2017\&file $=$ PO_98_4ta_Parte_20170620_1516_16.pdf

${ }^{47}$ En el artículo 3 fracción 20 señala que les compete promover el buen funcionamiento y estará a cargo de promover, evaluar y fortalecer el buen funcionamiento conforme a sus respectivas leyes, aplicando según su competencia las leyes en materia de responsabilidades. Ley de Responsabilidades de los Servidores Públicos, Periódico Oficial del Estado de Guanajuato, núm. 98, cuarta parte, 20 de junio del 2017, p. 3. 


\section{Ley Federal de Presupuesto y Responsabilidad Hacendaria}

Esta ley dispone las normas que delimitan el actuar universitario más allá de la buena fe, las identificadas como Reglas de operación $n^{48}$; la Universidad de Guanajuato está obligada a atender esta legislación por ser una persona de derecho público determinada en el artículo 3 de su Ley Orgánica mencionada.

\section{Ley General del Sistema Nacional Anticorrupción}

Se vislumbra que los pactos jurídicos incluyan, de manera ordinaria, cláusulas, compromisos y términos para atender el llamado a la cultura de la integridad y rendición de cuentas, de transparencia, fiscalización y control de los recursos públicos. La Universidad de Guanajuato deberá pactar con base en este nuevo enfoque, que se presenta con miras al Sistema Nacional Anticorrupción, localmente llamado Sistema Estatal Anticorrupción, establecido en la Carta Estatal.

Dentro de las acciones legales que el Estado mexicano ha establecido para erradicar la corrupción, en el año de 1982, el entonces presidente de la república señaló que era también responsabilidad del pueblo [...] En virtud de que la inmoralidad social afecta a todos y, por lo tanto, se tiene una gran responsabilidad en el cumplimiento de lo que demandamos y exigimos ${ }^{49}$. El comportamiento ético de todo servidor público será enmarcado en este nuevo paradigma, hoy resplandeciente pero que será el precedente de políticas públicas transversales.

La transparencia sienta las bases para crear un sistema electrónico a nivel nacional y local donde los acuerdos de buena fe deban ser expuestos para salvaguardar el manejo y destino del erario. En la Constitución Política para el Estado de Guanajuato se plantea el Sistema Estatal Anticorrupción en el precepto legal 132; aunque, resta ardua labor legislativa para la reglamentación de fiscalización en este rubro.

\section{Ley del Sistema Estatal Anticorrupción}

Tal como hemos expuesto, la buena fe y la libertad contractual señalan límites a la voluntad de la Universidad de Guanajuato, por lo que tendrá que responder al nuevo enfoque de anticorrupción. Con miras a la implementación del sistema anticorrupción local se publicó en el año 2017 la Ley del Sistema Estatal Anticorrupción, que tendrá alcance en el comportamiento ético de los servidores públicos y, por tanto, en su actuación al momento de la celebración y cumplimiento de los convenios.

\footnotetext{
${ }^{48}$ En el artículo 2 fracción 45 de la Ley Federal de Presupuesto y Responsabilidad Hacendaria podemos identificar a las reglas de operación definidas como las disposiciones a las cuales se sujetan-invariablemente los convenios - determinados programas y fondos federales con el objeto de otorgar transparencia y asegurar la aplicación eficiente, eficaz, oportuna y equitativa de los recursos públicos asignados a los mismos.

${ }^{49}$ Discurso de Miguel de La Madrid Hurtado en Garita Alonso, Arturo (2015), "El sistema anticorrupción en México", Revista Pluralidad y Consenso, México, Instituto Belisario Domínguez del Senado de la República, núm. 25, p. 180. El decreto publicado en el DOF el 14 de junio del 2002 reformó la denominación del título cuarto constitucional, estableciendo la responsabilidad patrimonial del Estado, que bien puede considerarse como un elemento de la responsabilidad administrativa de los servidores públicos. Ibídem., p. 182. Sucesivamente, en el año 2015, la reforma del Sistema Nacional Anticorrupción constituye un paradigma sin igual del combate a la corrupción. Ídem.
} 
La funcionalidad estará determinada por la reglamentación que los entes públicos emi$\tan ^{50}$, así como por la adopción que de las políticas públicas haga la institución universitaria en los acuerdos que suscriba. Irrefutable es su aplicación de conformidad con el artículo 3 fracción sexta. En este tenor, la libertad contractual universitaria va en camino de integrar supuestos normativos anticorrupción porque, en retrospectiva, los contratantes son servidores públicos y su comportamiento está previsto en dichos supuestos. La Universidad dará cuenta del seguimiento de las contrataciones públicas al formar parte del Sistema Estatal de Fiscalización de acuerdo con la citada ley ${ }^{51}$.

\section{Ley de Fiscalización Superior del Estado de Guanajuato ${ }^{52}$}

Esta normativa será aplicable a los acuerdos bilaterales en tanto se incluyan recursos públicos, los cuales, deben ser fiscalizados por parte de la Auditoría Superior del Estado de Guanajuato de acuerdo con el artículo 2 fracción cuarta y tercera.

\footnotetext{
${ }^{50}$ El artículo 3 lo señala, y para los efectos de la presente Ley se entenderá por: V. Entes públicos: los Poderes Ejecutivo, Legislativo y Judicial, así como sus entidades y dependencias; los organismos constitucionales autónomos; los municipios, sus dependencias y entidades; así como cualquier otro ente sobre el que tenga control cualquiera de los poderes y órganos públicos antes citados del Estado y municipios; VI. Órganos internos de control: los Órganos internos de control en los Entes públicos. Artículo 4. Son sujetos de la presente Ley, los Entes públicos que integran el Sistema Estatal. Artículo 5. Son principios rectores que rigen el servicio público, legalidad, objetividad, profesionalismo, honradez, lealtad, imparcialidad, eficiencia, eficacia, equidad, transparencia, economía, integridad y competencia por mérito. Los Entes públicos están obligados a crear y mantener condiciones estructurales y normativas que permitan el adecuado funcionamiento del Estado en su conjunto, y la actuación ética y responsable de cada servidor público. Secretaría de Gobierno (2017), Ley del Sistema Estatal Anticorrupción de Guanajuato, 29 de mayo del 2018 [en línea], disponible en: http://periodico.guanajuato.gob.mx/downloadfile? dir $=a-$ nio_2017\&file $=$ PO\%2078\%202da_20170516_1213_1.pdf

${ }^{51} \mathrm{El}$ artículo 42. El Sistema Estatal de Fiscalización tiene por objeto establecer acciones y mecanismos de coordinación entre los integrantes de este. En el ámbito de sus respectivas competencias, promoverán el intercambio de información, ideas y experiencias encaminadas a avanzar en el desarrollo de la fiscalización de los recursos públicos. El Sistema Estatal de Fiscalización está integrado por: I. La Auditoría Superior del Estado de Guanajuato; II. La Secretaría de la Transparencia y Rendición de Cuentas; III. Los Órganos Internos de Control de los Municipios; y IV. Los Órganos Internos de Control de los Poderes Legislativo y Judicial, y de los Organismos Autónomos constitucionales y legales.

Artículo 53. El Comité Coordinador emitirá las bases para el funcionamiento de la Plataforma Digital Estatal que permita cumplir con los procedimientos, obligaciones y disposiciones señaladas en la presente Ley y la Ley de Responsabilidades aplicable, así como para los sujetos de esta Ley, atendiendo a las necesidades de accesibilidad de los usuarios. La Plataforma Digital Estatal será administrada por la Secretaría Ejecutiva, a través del Secretario Técnico de la misma, en los términos de esta Ley.

Artículo 54. La Plataforma Digital Estatal del Sistema Estatal estará conformada por la información que a ella incorporen las autoridades integrantes del Sistema Estatal y contará, al menos, con los siguientes sistemas electrónicos: I. Sistema de evolución patrimonial, de declaración de intereses y constancia de presentación de declaración fiscal; II. Sistema de los Servidores públicos que intervengan en procedimientos de contrataciones públicas; III. Sistema estatal de Servidores públicos y particulares sancionados; IV. Sistema de información y comunicación del Sistema Estatal; V. Sistema de denuncias públicas de faltas administrativas y hechos de corrupción; y VI. Sistema de Información Pública de Contrataciones.

${ }^{52}$ Secretaría de Gobierno (2015), Ley de Fiscalización Superior del Estado de Guanajuato, 29 de mayo del 2018 [en línea], disponible en: http://periodico.guanajuato.gob.mx/downloadfile?dir=files_migrados\&file=PO_154_13Va_Parte_20150925_1929_20.pdf
} 


\section{Ley de Contrataciones Públicas para el Estado de Guanajuato}

Dicha norma regula, controla y vigila los actos o contratos que lleve a cabo la Universidad, como organismo autónomo, en materia de adquisiciones y arrendamientos, enfocándose en los bienes muebles e inmuebles, así como en la enajenación de éstos últimos y en los servicios de cualquier naturaleza que importe obligación de pago ${ }^{53}$.

\section{Conclusiones}

La buena fe es un valor moral específico que inspira a la conducta humana a sujetarse a ella para encontrar la verdad y dar sentido a la justicia; también señala los derechos y deberes de los individuos; y es el propósito que debe permear en la conducta de los hombres. Esta justicia, entendida como valor social, es la que debemos reafirmar al momento de plasmar la buena fe en la preparación, celebración y ejecución del pacto jurídico universitario, pues sólo a través de la confianza entre las partes podemos tener certeza en lo comprometido, es decir, en su cumplimiento. Esta certeza se logra gracias al sistema de normas internas y externas que coexisten alrededor de la materia contractual universitaria.

La construcción de nuestro discurso se basa en el trajín universitario y el irrestricto cumplimiento de sus compromisos jurídicos, los cuales dan seguridad jurídica a los partícipes de un contrato y a la sociedad de la cual forma parte. De este modo, la Universidad de Guanajuato se coloca a sí misma como una institución que fomenta la eficiencia de sus relaciones jurídicas con el mayor beneficio porque su perspectiva de trabajo nace y se prolonga en la buena fe, con sustento en las normas jurídicas y sin necesidad de razones para la acción.

La efervescencia del Sistema Estatal Anticorrupción tiene la legítima pretensión de salvaguardar el comportamiento ético de los servidores públicos y erradicar conductas que no abonan a la transparencia, fiscalización y rendición de cuentas, labor que corresponde al órgano de control interno universitario, entre otros entes.

\section{Bibliografía}

Aguilar Carvajal, Leopoldo (1964), Contratos Civiles, México, Hagtam.

AtienzA, Manuel (2011), Introducción al derecho, México, Editorial Fontamara.

Atienza, Manuel y Ruiz Manero, Juan (1951), Sobre Principios y Reglas. [en línea] disponible en: http://www.cervantesvirtual.com/descargaPdf/sobre-principios-y-reglas-O.pdf (consultada el 27 de mayo del 2018).

\footnotetext{
${ }^{53}$ P.O. número 206 de 26 de diciembre del 2014. El artículo 7 fracción primera hace la exclusión de la ley de los convenios o contratos que celebren entre sí los sujetos de esta ley o entre estos y la Federación, con otras entidades federativas o con los municipios. Empero, el último párrafo dicta los actos o contratos deberán llevarse a cabo en apego a lo establecido en el primer párrafo del artículo 134 de la Constitución Política de los Estados Unidos Mexicanos, previéndose por los sujetos de la ley las mejores condiciones disponibles en cuanto a precio, financiamiento, calidad, oportunidad y demás circunstancias que contribuyan a preservar la hacienda pública estatal. Secretaría de Gobierno (2014), Ley de Contrataciones Públicas para el Estado de Guanajuato, 29 de mayo del 2018 [en línea], disponible en: http://periodico.guanajuato.gob.mx/ downloadfile?dir=files_migrados\&file $=P O \_206 \_15 v a \_P a r t e \_20141223 \_1123$ 3.pdf
} 
Calsamiglia, Albert (1993), Racionalidad y Eficiencia del derecho, México, Editorial Fontamara.

CAStrillón Y Luna, Víctor (2008), "La libertad contractual”, Revista de la Facultad de Derecho de México, núm. 250, p. 156. [en línea] disponible en: https://revistas. unam.mx/indez.php/rfdm/article/view/60936/53740. (Consultada el día 7 de mayo del 2018).

Comanducci, Paolo (2004), Razonamiento jurídico, elementos para un modelo, México, Editorial Fontamara.

Congreso Constitucional del Estado Libre y Soberano de Guanajuato (2016), Código civil para el estado de Guanajuato, Periódico Oficial del Gobierno del estado de Guanajuato, 29 de mayo del 2018, [en línea] disponible en: http://imug.guanajuato.gob. $\mathrm{mx} /$ wp-content/uploads/2017/05/C\%C3\%B3digo-Civil-para-el-Estado-de-Guanajuato.pdf

Coviello, Nicolás (1938), Doctrina General del Derecho Civil, traduc. Felipe de J. Tena, México, Unión Tipográfica Editorial Hispano-Americana.

De Buen Lozano, Néstor (2004), "La decadencia del contrato" con dos apéndices Veinte Años Después y Los tenues suspiros de la libertad contractual, $4^{\mathrm{a}}$. ed., México, Porrúa.

Flores García, Fernando (2008), Los fines del derecho, México, Porrúa.

Galindo Garfias, Ignacio (1981), "Estudios de derecho civil”, México, UNAM, Instituto de Investigaciones Jurídicas, p. 359. [en línea] disponible en: https://archivos.juridicas.unam.mx/www/bjv/detalle-libro/876-estudios-de-derecho-civil (consultada el 21 de febrero de 2018).

Garita Alonso, Arturo (2015), "El sistema anticorrupción en México", Revista Pluralidad y Consenso, México, Instituto Belisario Domínguez del Senado de la República, núm. 25.

GutiérRez Y GonzÁLez, Ernesto (1982), "El Principio de la buena fe en el derecho civil", Revista de la Facultad de Derecho de México, s.p.i., núm. 124-125-126, p.621. [en línea] disponible en: https://revistas-colaboracion.juridicas.unam.mx/index.php/rev-facultad-derecho-mx/article/view/27427/24767 (Consultada el 5 de febrero del 2018).

JimÉNEz GómEZ, Juan Ricardo (1985), "El principio de la buena fe en la teoría general del contrato" en GALINDO GARFIAS, Ignacio, et.al., Un siglo de derecho civil mexicano: memoria del II Coloquio Nacional de Derecho Civil. 1884-1984, México, Universidad Nacional Autónoma de México.

Lastra Lastra, José Manuel (2003), "La buena fe en el trabajo: ¿Un principio que se difumina?", Revista de la Facultad de Derecho de México, núm. 240, p. 109. [en línea] disponible en: https://revistas-colaboracion.juridicas.unam.mx/index/php/ rev-facultad-derecho-mx/article/view/28653/25908 (consultada el 31 de enero de 2018).

López Monroy, José de Jesús (1986), "El Principio de la buena fe en el derecho civil", Revista de la Facultad de Derecho de México, 1986, núm. 145-146-147, p.165. [en línea] disponible en: https://revistas-colaboracion.juridicas.unam.mx/index.php/ rev-facultad-derecho-mx/article/view/27614/24943 (Consultada el 5 de febrero del 2018) 
Muñoz, Luis (1971), Derecho Civil Mexicano, t. III., México, Ediciones Modelo. (1973), Teoría General del Contrato, México, Cárdenas, Editor y Distribuidor.

Olivecrona, Karl (2004), Lenguaje Jurídico y Realidad, Biblioteca de Ética, Filosofía del Derecho y Política, México, Ediciones Coyoacán, Distribuciones Fontamara.

Ribeiro Toral, Gerardo (2007), Verdad y argumentación jurídica, México, Porrúa.

Rodríguez-Arana, Jaime (2013), "El principio general del derecho de confianza legítima”, Revista Ciencia Jurídica, Universidad de Guanajuato, núm. 1-4, julio.

Sánchez Medal, Ramón (1991), De los contratos civiles, 11ª . ed., México, Porrúa.

Secretaría de Gobierno (2014), Ley de Contrataciones Públicas para el Estado de Guanajuato, 29 de mayo del 2018 [en línea] disponible en: http://periodico.guanajuato.gob.mx/downloadfile?dir=files_migrados\&file=PO_206_15va_Parte_20141223_1123_3.pdf

Secretaría de Gobierno (2015), Ley de Fiscalización Superior del Estado de Guanajuato, 29 de mayo del 2018 [en línea] disponible en: http://periodico.guanajuato.gob.mx/ downloadfile?dir=files_migrados\&file=PO_154_13Va_Parte_20150925_1929_20. pdf

Secretaría de Gobierno (2016), Ley de Transparencia y Acceso a la Información Pública para el estado de Guanajuato, 29 de mayo del 2018 [en línea] disponible en: http:// periodico.guanajuato.gob.mx/downloadfile?dir=files_migrados\&file=PO_77_3ra Parte_20160513_1847_12.pdf

Secretaría de Gobierno (2017), Ley del Sistema Estatal Anticorrupción de Guanajuato, 29 de mayo del 2018 [en línea] disponible en: http://periodico.guanajuato.gob.mx/ downloadfile?dir=anio_2017\&file=PO\%2078\%202da_20170516_1213_1.pdf

Secretaría de Gobierno (2017), Ley de Responsabilidades Administrativas para el Estado de Guanajuato, 29 de mayo del 2018 [en línea] disponible en: http://periodico.guanajuato.gob.mx/downloadfile?dir=anio_2017\&file=PO_98_4ta_Parte_20170620_1516_16.pdf

Secretaría de Gobierno (2016), Reformas Ley Orgánica de la Universidad de Guanajuato, Periódico Oficial del Gobierno del Estado, 29 de mayo del 2018 [en línea] disponible en: http://periodico.guanajuato.gob.mx/downloadfile?dir=anio_2016\&file=PO_207_7ma_Parte_20161229_0112_10.pdf

Secretaría de Gobierno (2014), Ley de Contrataciones Públicas para el Estado de Guanajuato, 29 de mayo del 2018 [en línea] disponible en: http://periodico.guanajuato.gob.mx/downloadfile?dir=files_migrados\&file=PO_206_15va_Parte_20141223_1123_3.pdf

TAMAYO Y SALMORÁn, Rolando (2007), Razonamiento y argumentación jurídica. El paradigma de la racionalidad y la ciencia del derecho, México, UNAM.

Universidad de Guanajuato (s.f.), Código De Ética De La Universidad De Guanajuato. [en línea] disponible en: http://www.ugto.mx/images/pdf/normatividad/codigo-etica-universidad-guanajuato.pdf (consultada el 21 de febrero de 2018). 
Universidad de Guanajuato (2008), Estatuto Orgánico de la Universidad de Guanajuato. [en línea] disponible en: http://www.ugto.mx/images/pdf/normatividad/estatuto-organico-universidad-guanajuato.pdf (consultada el 21 de febrero de 2018).

Universidad de Guanajuato (2007), Ley Orgánica de la Universidad de Guanajuato. [en línea] disponible en: http://www.ugto.mx/images/pdf/normatividad/ley-organica-universidad-guanajuato.pdf (consultada el 21 de febrero de 2018). 